\title{
Primary Descriptions of Defense Mechanisms Employed by Neotropical Salamanders (Bolitoglossa, Oedipina, Nototriton, and Cryptotriton sp.: Plethodontidae) in Cusuco National Park, Honduras
}

Cristina Arrivillaga ${ }^{1,2}$ and Tom W. Brown ${ }^{1,2}$

\begin{abstract}
1'Operation Wallacea, Hope House, Old Bolingbroke, Lincolnshire PE23 4EX, UK (cristinaarrivillaga@gmail.com)
\end{abstract}
${ }^{2}$ Kanahau Utila Research and Conservation Facility, Isla de Utila, Honduras

$\mathrm{T}_{\mathrm{H}}^{\mathrm{h}}$ he herpetofauna of Cusuco National Park (CNP), Honduras is extremely diverse, with a total of 73 reptiles and 28 amphibians recorded within its approximately 23,000-hectare boundary (Gilroy et al. 2017). Le Saout et al. (2013) considered the park to be the 25th most irreplaceable global locality for amphibian biodiversity. This is largely attributable to the park's heterogeneous topography, diverse range of habitats, and number of species (Stuart et al. 2008). This amphibian diversity is reflected in the nine recorded plethodontid salamander species, six of which belong to the subfamily Bolitoglossinae. Eight of the nine species in the park have been assessed for the IUCN Red List, with four (Bolitoglossa conanti, B. dunni, Cryptotriton nasalis, Nototriton brodiei) considered Endangered (Cruz et al. 2010a; IUCN SSC Amphibian Specialist Group 2014a, 2014b, 2014c), and two (B. diaphora and Oedipina tomasi) classified as Critically Endangered (Cruz et al. 2010b; Castañeda 2008). Moreover, the latter two species are endemic to Cusuco National Park, whereas three (B. dunni, C. nasalis, $N$. brodiei) have restricted distributions and are co-endemic with Guatemala.

Salamanders are increasingly threatened, part of the approximately $32 \%$ of the world's amphibians facing possible extinction according to the Global Amphibian Assessment (GGA) of 2004 (Stuart et al. 2004). Furthermore, many Neotropical species have restricted distributions, live secretive lifestyles, and are rarely observed (e.g., Nototriton brodiei, which is known from fewer than 10 specimens; IUCN SSC Amphibian Specialist Group 2014c). Consequently, we know very little about their ecology or natural history, and every encounter can provide valuable information.

Herein we document numerous observations regarding defense mechanisms employed by salamanders in the park for predator deterrence and avoidance. Our most notewor- thy observations were those involving physical escape mechanisms such as jumping in Nototriton brodiei; body-flipping in Oedipina tomasi; tail autotomy in Cryptotriton nasalis, Bolitoglossa dolfleini, and B. mexicana; and the presence of adhesive anti-predator skin secretions in $B$. conanti, $B$. diaphora, and $B$. dunni. Additionally, we report what might have been a mutually beneficial relationship between ants and a burrowing adult female $B$. dolflieni. All of these observations were made during long-term annual herpetology research and monitoring facilitated by Operation Wallacea conducted in Cusuco National Park, Honduras in June-August 2012-2017.

\section{Observations}

The salamander defense mechanisms we observed can be classified broadly into four general categories: Posturing, body-flipping, tail autotomy, and skin secretions. Many of these behaviors have been previously documented in other salamander species (e.g., Brodie 1977) and within the genera Bolitoglossa and Oedipina (Brodie and Ducey 1991; Smits and Brodie 1995; Lee 2000; Savage 2002; Itgen and Sessions 2016). Herein we describe previously unknown behaviors for several salamander species.

When amphibians are captured for the collection of morphometric data, they are inevitably subject to stress. Consequently, they often deploy defensive adaptations as if being attacked by a predator. While stressing the animals was unintentional, it did provide an opportunity to document defensive behaviors. Please note, however, that at no point were salamanders in contact with human skin. Capture and subsequent data collection were done using a moist sterile plastic bag at all times. All individuals were processed quickly and ethically and were not subjected to any additional stress beyond that associated with collecting morphological data. 


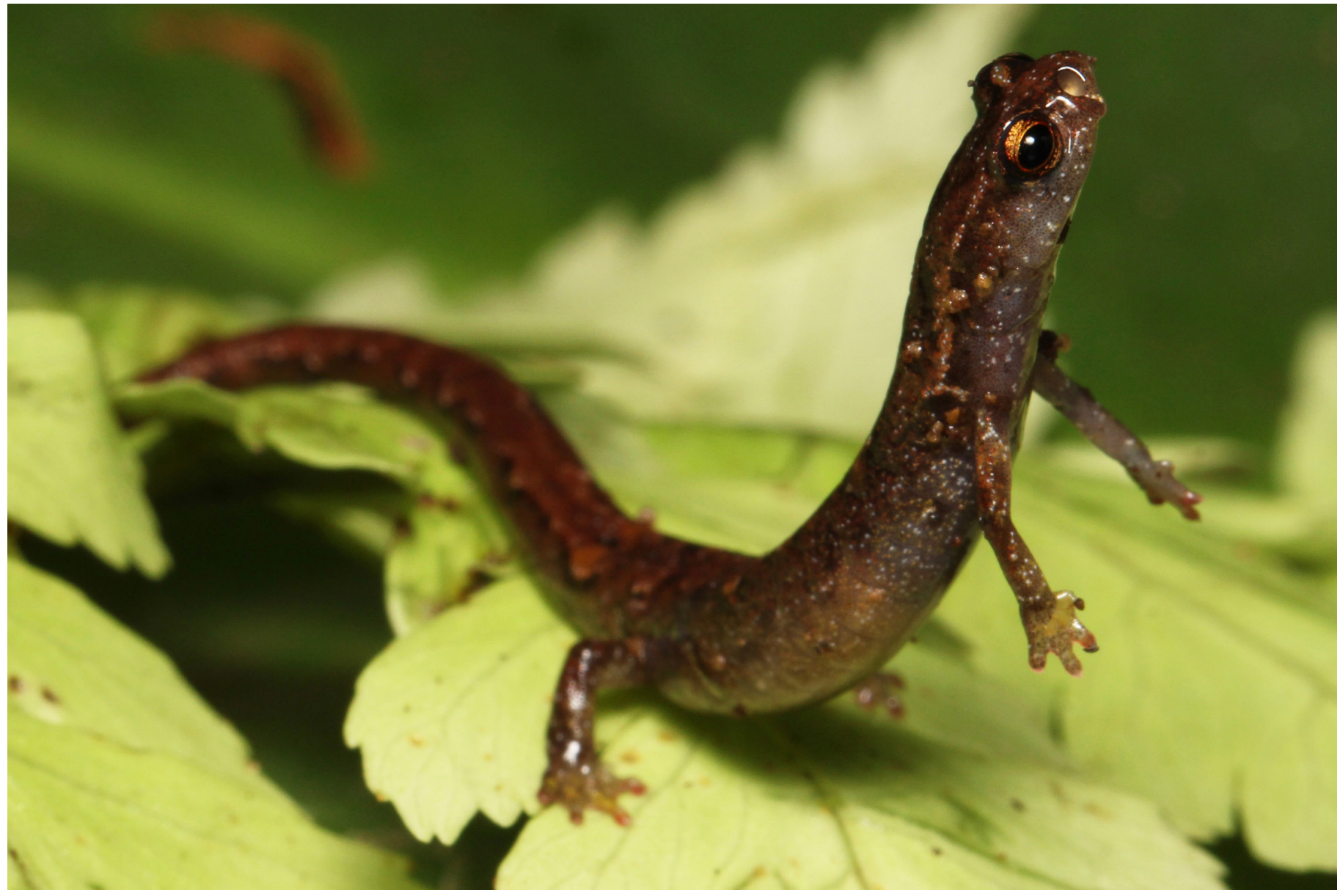

Fig. 1. Cryptotriton nasalis adopts and mantains an elevated defensive posture when threatened. This display may be an effort to appear larger and confuse potential predators. Photograph by Edward Evans.

Posturing.-Posturing as an antipredator defense includes any position a prey animal adopts in order to enhance its chance of surviving against a predator (Brodie 1977). Few species in CNP have been observed posturing as an antipredator defense (exceptions include Cryptotriton nasalis and Bolitoglossa nympha). When an individual of these species feels threatened, it elevates the anterior part of its body and sustains that position until the apparent danger has passed (Fig. 1). In most terrestrial salamanders, antipredator postures often are associated with skin secretions, either by exposing the ventral aposematic coloration or orientating its glands toward the predator (Brodie and Gibson 1969). No evidence currently indicates that $C$. nasalis has noxious skin secretions or aposematic ventral coloration, therefore the origin of the elevated posture we observed is most likely an attempt to appear bigger and more threatening. In addition to posturing, $C$. nasalis also employed body-flipping and tail autotomy.

Body-flipping.-At ca. 0430 h on 13 June 2017, we encountered an active adult Nototriton brodiei on the surface of a mossy log within $500 \mathrm{~m}$ of the CNP visitor center $\left(15.4964^{\circ} \mathrm{N}, 88.21186^{\circ} \mathrm{W}\right.$; WGS 84; elev. 1,575 m). Because we have only two records of this species since 2007 (C. Vásquez-Almazán pers. comm. 2014; J. Kolby pers. comm.
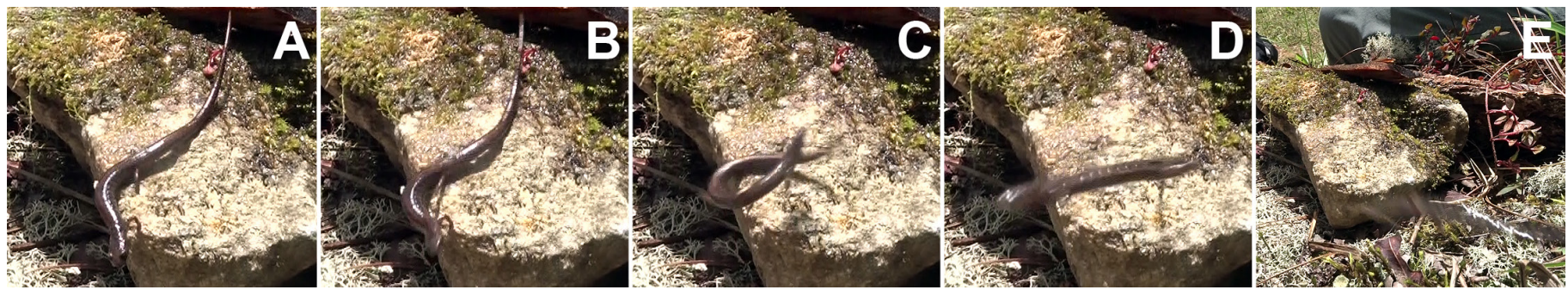

Fig. 2. Stop-motion images taken from a 0.6-sec video sequence showing body-flipping by Nototriton brodiei from a resting position (A), followed by coiling of the body and propulsion via tail-flicking (B/C), and airborne (D/E). Video by Tom W. Brown. 
2012), any observations of natural history are of considerable interest. This individual weighed $0.3 \mathrm{~g}$; SVL measured 23 $\mathrm{mm}$ and tail length (TL) $39 \mathrm{~mm}$. Upon release, we observed an impressive "jumping" escape mechanism. On further analysis of this locomotion (Fig. 2), we determined that the salamander used a quick flick of its tail to propel itself away from a potential threat. The sequence shown lasted $0.6 \mathrm{sec}$, and could only be identified after examining slow-motion video and extracting still images. We also observed such tail-flicking behavior in Cryptotriton nasalis.

Savage (2002) described body-flipping as a technique used by salamanders in the genus Oedipina as a means of defense against predators, especially if the disturbance is violent or if the salamander is touched. Brodie (1977) reported many salamanders respond to predators by flipping the body or coiling and uncoiling rapidly in order to "jump" and switch locations, thus confusing the predator and aiding its escape to safety. Body-flipping is an erratic and unpredictable movement that disorients predators leaving them unable to predict where the salamander is going. Moreover, erratic flipping often is followed by sudden and complete inactivity, a switch of escape mechanisms to a reliance on the salamander's cryptic coloration to escape detection. We observed this behavior in C. nasalis, N. brodiei, and O. tomasi, all of which are known to have exceptionally elongated and slender bodies when compared to species of the genus Bolitoglossa, suggesting that this defensive technique is best suited for salamanders with this morphology_although Leenders and WatkinsColwell (2003) documented an instance of such behavior in B. colonnea.

Tail autotomy.-We observed evidence of tail autotomy (individuals with dropped tails or signs of tail regeneration and a dropped tail of a salamander thought to be Nototriton given its locality, length, and coloration) in three of the four genera of salamanders in CNP. The most common observations of tail loss or regeneration were for species in the genus Bolitoglossa, including B. mexicana, B. dofleini (Figs. 3a, 3b), $B$. conanti, and $B$. diaphora, and we believe that this adaptation is likely employed by most or all species in the genus.
We also recorded instances of autotomy in Cryptotriton nasalis (Fig. 3c) and Oedipina tomasi.

Lee (2000) reported tail autotomy for Bolitoglossa rufescens, describing it as the most common anti-predator defense used by species of Bolitoglossa and noting that the tail is raised and "effortlessly" lost in order to present it to a possible predator. Itgen and Sessions (2016) also reported tail autotomy in several species of Bolitoglossa (B. mexicana, B. dunni, and $B$. dofleini). Tail autotomy also is known to occur in a number of plethodontids, including Oedipina uniformis (Smits and Brodie 1995). As in many species of lizards (e.g., Higham and Russell 2010; Higham et al. 2013), after the tail has been "lost" or "dropped," muscles contract and cause the tail to flip and undulate, which confuses and distracts the predator while the salamander escapes (Wake and Dresner 1967). Even though plethodontids are lungless and rely on their skin for respiration, Smits and Brodie (1995) demonstrated that tail autotomy does not impose a major respiratory cost in Oedipina uniformis.

Skin secretions.-We observed three species of Bolitoglossa (B. diaphora, B. conanti, B. dunni) from CNP actively secreting substances from their skin when captured. Bolitoglossa diaphora secreted a pale milky substance, whereas $B$. dunni and B. conanti (Fig. 4) produced yellow secretions. All had adhesive properties, effectively gluing together the plastic bags in which the salamanders were held (for adhesive strength of amphibian skin secretions see Evans and Brodie 1994). In $B$. dunni, the yellow secretion appeared to have a latex-like odor. Parra-Olea et al. (2004) indicated that these three species appear to be more closely related to each other than to other species of the $B$. dunni group, which could explain why they are the only species from the park we observed employing this defensive mechanism. Unfortunately, analysis of these secretions was not within the scope of this observational study.

Skin secretions are a high-cost adaptation against predators; even so, most terrestrial salamanders utilize noxious skin secretions as their primary defense (e.g., Brodie 1983). In the genus Bolitoglossa, some species such as $B$. rostrata and $B$. subpalmata have been found to produce toxic skin secretions
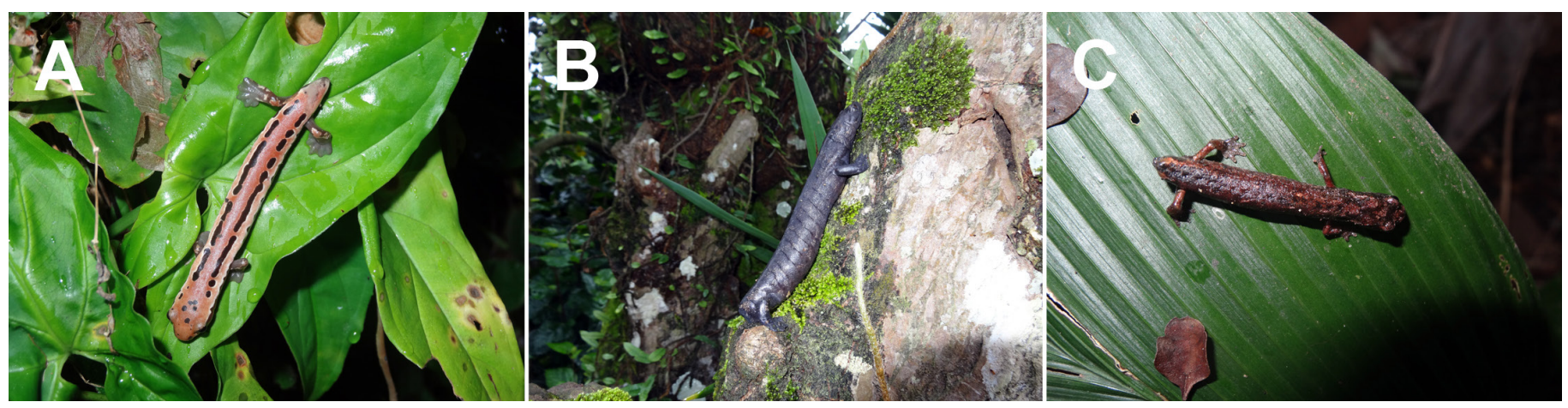

Fig. 3. Tail autotomy and regeneration in Bolitoglossa mexicana (A), B. dofleini (B), and Cryptotriton nasalis (C). Photographs by Tom W. Brown. 

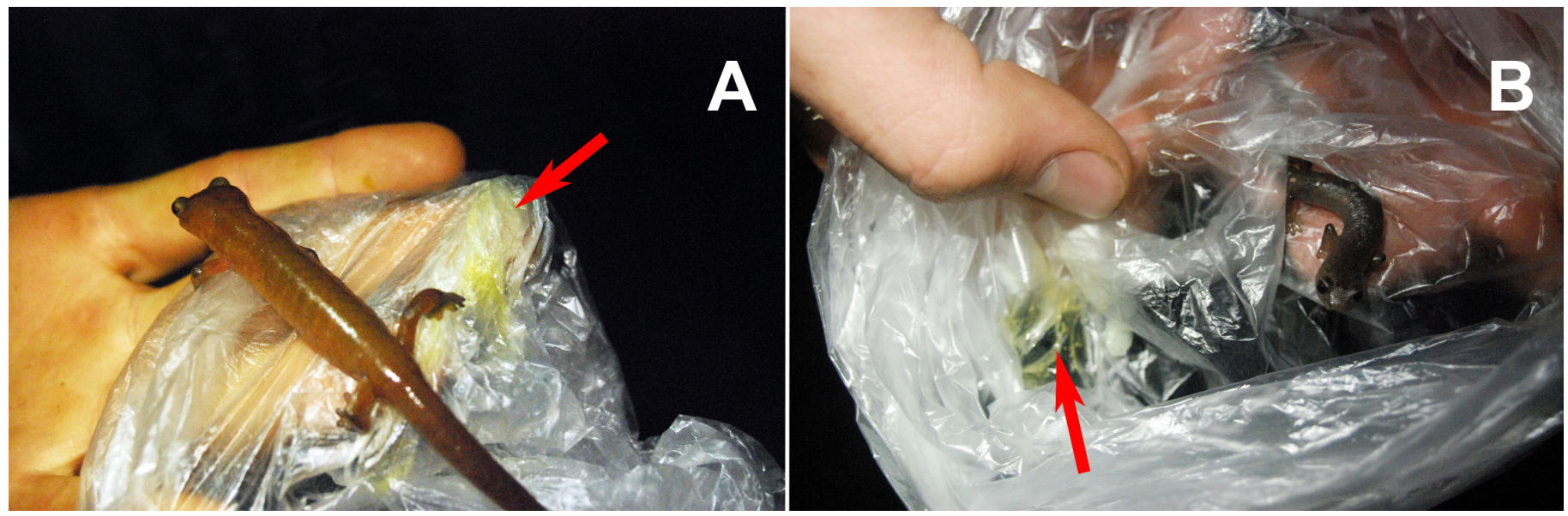

Fig. 4. Bolitoglossa dunni (A) and adhesive yellow skin secretions; Bolitoglossa conanti (B) secreted a similiar yellow substance (B). Photographs by Cristina Arrivillaga.

that can cause paralysis of the mouth and even death in snake predators (Brodie et al. 1991). Other salamander species have been found to immobilize predators by applying an adhesive secretion to the jaws and head of a snake through body movements (Arnold 1982). Adhesive secretions could provide additional defensive mechanisms, such as sticking predators to substrates or even gluing leaves and other surrounding material to the salamander's body, making it harder to eat and swallow (Evans and Brodie 1994). Although Dodd and Brodie (1979) recorded adhesive skin secretions in Bolitoglossa flavimembris, information on and records of skin secretions of salamanders in the genus Bolitoglossa are surprisingly deficient.

An apparent mutually beneficial association.-At 1900 h on 9 July 2015, we encountered a large adult female Bolitoglossa dofleini partially emergent in a burrow adjacent to coffee plantations and pasture in the local village of Buenos Aires. Once alerted to our presence, the salamander retreated immediately into its burrow, which we then proceeded to carefully excavate. As we began to dig, we realized that the tunnel was co-inhabited by small, unidentified ants, which proceeded to relentlessly bite and sting our hands. The tunnel entrance was approximately $6 \mathrm{~cm}$ wide and extended about $30 \mathrm{~cm}$ before widening into a larger damp pocket from which we retrieved the salamander. The adult female salamander had a SVL of $117 \mathrm{~mm}$, tail length of $16.3 \mathrm{~mm}$, and weighed 39 g. Coincidently, this individual also showed recent signs of tail autotomy (Fig. 2b).

Our observation of ants cohabitating a burrow occupied by $B$. dofleini, is the first report of facultative proto-cooperation between amphibians and invertebrates in Honduras. We found that the ants actively attacked intruders, but did not exhibit any aggressive behaviors toward the salamander. Accordingly, we believe the ants might have provided some degree of protection for the salamander while exploiting the burrow's microhabitat.

\section{Acknowledgements}

We thank Operation Wallacea for facilitating our research of the unique herpetofauna of Cusuco National Park, as well as all the participating volunteers who assisted with these observations. Special thanks go to Samuel Jones, Thais Lopez, Cameron Thorpe, Frederick Barroso, Patrick Hennessy, George Lonsdale, and the local community/field guides of Buenos Aires. All herpetological data collection was performed under valid biological research and collection permits (Dictamen técnico ICF-DVS-104-2016; ICF-193-2016) issued to Operation Wallacea by the Instituto Nacional de Conservación y Desarrollo Forestal, Áreas Protegidas y Vida Silvestre (ICF), Tegucicalpa, Honduras.

\section{Literature Cited}

Arnold, S.J. 1982. A quantitative approach to antipredator performance: Salamander defense against snake attack. Copeia 1982: 247-253.

Brodie, E.D., Jr. 1977. Salamander antipredator postures. Copeia 1977: 523-535.

Brodie, E.D., Jr. 1983. Antipredator adaptations of salamanders: Evolution and convergence among terrestrial species, pp. 109-133. In: N.S. Margaris, M. Arianoutsou-Faraggitaki, and R.J. Reiter (eds.), Plant, Animal, and Microbial Adaptations to Terrestrial Environments. Plenum, New York, New York.

Brodie, E.D., Jr. and L.S. Gibson. 1969. Defensive behavior and skin glands of the Northwestern Salamander, Ambystoma gracile. Herpetologica 25: 187-194.

Brodie, E.D., Jr., P.K. Ducey, and E. Banes. 1991. Antipredator skin secretions of some tropical salamanders (Bolitoglossa) are toxic to snake predators. Biotropica 23: 58-62.

Castañeda, F. 2008. Oedipina tomasi. The IUCN Red List of Threatened Species 2008: e.T136010A4227602 (http://dx.doi.org/10.2305/IUCN.UK.2008. RLTS.T136010A4227602.en).

Cruz, G., L.D. Wilson, R. McCranie, F. Castañeda, C. Vásquez, S. Rovito, and J. Kolby. 2010a. Bolitoglossa conanti. The IUCN Red List of Threatened Species 2010: e.T59149A11890110 (http://dx.doi.org/10.2305/IUCN.UK.2010-2. RLTS.T59149A11890110.en).

Cruz, G., L.D. Wilson, R. McCranie, F. Castañeda, and J. Kolby. 2010b. Bolitoglossa diaphora. The IUCN Red List of Threatened Species 2010: e.T59153A11890904 (http://dx.doi.org/10.2305/IUCN.UK.2010-2.RLTS. T59153A11890904.en).

Dodd, C.K. and E.D. Brodie, Jr. 1976. Defensive mechanisms of Neotropical salamanders with an experimental analysis of immobility and the effect of temperature on immobility. Herpetologica 32: 269-290.

Evans, C.M. and E.D. Brodie, Jr. 1994. Adhesive strength of amphibian skin secretions. Journal of Herpetology 28: 499-502. 
Gilroy, D., S. Jones, K. Vulinec, P. Thompson, H. Hoskins, T. Creedy, M. Jocque, S. Green, G. Lonsdale, C. Phipps, O. Burdekin, and T. Brown. 2017. Operation Wallacea Cusuco National Park, Honduras 2016 \& 2017: End of Season Report (https:/www.opwall.com/uploads/2018/01/OpwallHonduras-Cusuco-End-of-Season-Report-2017.pdf).

Higham, T.E. and A.P. Russell. 2010. Flip, flop and fly: Modulated motor control and highly variable movement patterns of autotomized gecko tails. Biology Letters 6: 70-73.

Higham, T.E., A.P. Russell, and P.A. Zani. 2013. Integrative biology of tail autotomy in lizards. Physiological and Biochemical Zoology 86: 603-610.

Itgen, M.W. and S.K. Sessions. 2016. Tail autotomy as an anti-predator weapon in Neotropical plethodontid salamanders of the genus Bolitoglossa. Copeia 104: $182-188$.

IUCN SSC Amphibian Specialist Group. 2014a. Bolitoglossa dunni. The IUCN Red List of Threatened Species 2014: e.T59157A54374501 (http://dx.doi. org/10.2305/IUCN.UK.2014-3.RLTS.T59157A54374501.en).

IUCN SSC Amphibian Specialist Group. 2014b. Cryptotriton nasalis. The IUCN Red List of Threatened Species 2014: e.T61545710A54377069 (http://dx.doi. org/10.2305/IUCN.UK.2014-3.RLTS.T61545710A54377069.en).

IUCN SSC Amphibian Specialist Group. 2014c. Nototriton brodiei. The IUCN Red List of Threatened Species 2014: e.T29426A2790023 (http://dx.doi. org/10.2305/IUCN.UK.2014-3.RLTS.T29426A2790023.en).

Le Saout, S., M. Hoffmann, S.Yichuan, A. Hughes, C. Bernard, T.M. Brooks, B. Bertzky, S.H.M. Butchart, S.N. Stuart, T. Badman, and A.S.L. Rodrigues.
2013. Conservation. Protected areas and effective biodiversity conservation. Science 342: 803-805.

Leenders, T. and G.J. Watkins-Colwell. 2003. Morphological and behavioral adaptations in Bolitoglossa colonnea (Caudata, Plethodontidae) in relation to habitat use and daily activity cycle. Phyllomedusa 2: 101-104.

Parra-Olea, G., M. García-París, and D.B. Wake. 2004. Molecular diversification of salamanders of the tropical American genus Bolitoglossa (Caudata: Plethodontidae) and its evolutionary and biogeographical implications. Biological Journal of the Linnean Society 81: 325-346.

Savage, J.M. 2002. The Amphibians and Reptiles of Costa Rica - A Herpetofauna Between Two Continents, Between Two Seas. University of Chicago Press, Chicago, Illinois.

Smits, A.W. and E.B. Brodie, Jr. 1995. Lack of respiratory "cost" of tail autotomy in the lungless salamander, Oedipina uniformis. Comparative Biochemistry and Physiology 111A: 155-161.

Stuart, S.N., J.S. Chanson, N.A. Cox, B.E. Young, A.S.L. Rodrigues, D.L. Fischman, and R.W. Waller. 2004. Status and trends of amphibian declines and extinctions worldwide. Science 306: 1783-1786.

Stuart, S.N., M. Hoffman, J.S. Chanson, N.A. Cox, R.J. Berridge, P. Ramani, and B.E. Young. 2008. Threatened Amphibians of the World. Lynx Edicions, Barcelona, Spain; IUCN, Gland, Switzerland; and Conservation International, Arlington, Virginia, USA.

Wake, D.B. and I.G. Dresner. 1967. Functional morphology and evolution of tail autotomy in salamanders. Journal of Morphology 122: 265-305. 